\title{
INFLUÊNCIA DA TEMPERATURA NO COMPORTAMENTO REOLÓGICO DE GELEIAS COMERCIAIS DE CUPUAÇU (Theobroma grandiflorum)
}

\author{
Luzimary de Jesus Ferreira Godinho Rocha ${ }^{1}$ (luzimary@ifma.edu.br);Ocilene Maria Correia \\ Ferreira $^{2}$; Valdênia Cristina Mendes Mendonça ${ }^{2}$; Rachel Fernandes Torquato ${ }^{2}$; Francisco José \\ da Conceição Lima ${ }^{2}$; Javier Telis-Romero ${ }^{3}$; José Francisco Lopes Filho ${ }^{3}$. \\ ${ }^{1}$ Instituto Federal de Educação, Ciência e Tecnologia do Maranhão, Campus São Luís- Monte Castelo (IFMA), \\ Brasil. \\ ${ }^{1}$ Instituto Federal de Educação, Ciência e Tecnologia do Maranhão, Campus São Luís-Maracanã (IFMA), \\ Brasil. \\ ${ }^{2}$ Universidade Estadual Paulista, Campus de São José do Rio Preto (UNESP), Departamento de Engenharia e \\ Tecnologia de Alimentos, Brasil
}

Introdução: A Reologia é a ciência que estuda as propriedades mecânicas dos materiais que determinam seu escoamento quando solicitadas por forças externas. As frutas nativas da Amazônia Brasileira despertam um grande interesse mundial quanto à sua composição nutricional e valor comercial. Com o cupuaçu (Theobroma grandiflorum) não é diferente, pois tal fruta, além de exótica, apresenta inúmeras formas de ser consumida, tais como: doces, geleias, sucos, sorvete, mousse e até em forma de licores. O cupuaçu pode, ainda, ser usado em produtos cosméticos, utilizando a parte gordurosa do fruto, suas sementes contém alto valor proteico e servem para incorporar vários tipos de alimentos. As geleias são doces semitransparentes, contendo polpa do fruto em partes de açúcar, que são cozidos até obter uma consistência viscosa, a pectina das frutas garante essa propriedade física. Objetivos: Determinar o comportamento reológico de uma geleia comercial de cupuaçu nas temperaturas de $20^{\circ} \mathrm{C}, 30^{\circ} \mathrm{C}, 40^{\circ} \mathrm{C}, 50^{\circ} \mathrm{C}$ e $60^{\circ} \mathrm{C}$ e identificar o modelo mais adequado para descrever o comportamento reológico desse tipo de alimento, a fim de se obter parâmetros para a produção deste tipo de produto. Material e métodos: As geleias foram adquiridas no comércio local da cidade de São Luís, no estado do Maranhão. As análises reológicas foram determinadas por um reômetro rotacional do tipo cone e placa, localizado no DETA/UNESP. Resultados: Os dados experimentais foram ajustados aos modelos de Newton, Ostwald-de-Waelle e Bingham, sendo que o modelo mais adequado para descrever o comportamento reológico do produto estudado foi o de Ostwald-de-Waelle, pois apresentou coeficientes de determinação $\left(R^{2}\right)$ superiores a 0,99 e menores valores de erro em todas as temperaturas estudadas. O tempo para formação dos géis foi de aproximadamente 50 minutos (300s). Conclusão: As amostras apresentaram comportamento não newtoniano e caráter pseudoplástico.

Palavras-chave: cupuaçu; modelos; reogramas. 